\title{
Determination of Regional Bone Blood Flow by Means of Fluorescent Microspheres Using an Automated Sample-Processing Procedure
}

\author{
H. Anetzberger ${ }^{a, b} \quad$ E. Thein ${ }^{b} \quad$ A.K. Wallic K. Messmer ${ }^{b}$ \\ aDepartment of Orthopedics, b Institute for Surgical Research, and 'Institute for Clinical Chemistry, \\ Klinikum Grosshadern, Ludwig Maximilians University, Munich, Germany
}

\section{Key Words}

Bone blood flow · Fluorescent microspheres - Animal experiments

\begin{abstract}
The determination of regional blood flow utilizing fluorescent microspheres (FMs) is an established method for numerous organs. Recent progress, in particular the automation of sample processing, has further improved this method. However, the FM method (reference sample technique), which allows repetitive measurement of regional organ blood flow, has so far not been used for the determination of blood flow in bone. The aim of the present study was to establish FM for the quantification of regional bone blood flow (RBBF). Female, anesthetized New Zealand rabbits $(n=6)$ received left ventricular injections of different amounts of FM at six subsequent time points. In order to examine the precision of RBBF determination, two different FM species were injected simultaneously at the sixth injection. At the end of the experiments the femoral and tibial condyles of each hind limb were removed and the fluorescence intensity in the tissue samples was measured by an automated procedure. In an in vitro study we have shown that acid digestion of the crystalline matrix has no effect on the fluorescence characteristics of FM. The determination of the
\end{abstract}

number of spheres per tissue sample revealed that depending on the tissue sample size up to $3 \times 10^{6}$ spheres/ injection were necessary to obtain about 400 microspheres in the individual bone samples. RBBF values of the tibial and femoral condyles did not differ at various injection intervals. The tibial blood flow values varied between $6.6 \pm 1.1$ and $8.5 \pm 1.4 \mathrm{ml} / \mathrm{min} / 100 \mathrm{~g}$ and were significantly higher than those of the femur $(4.3 \pm 1.1$ to $6.0 \pm 1.8 \mathrm{ml} / \mathrm{min} / 100 \mathrm{~g}$ ). The bone blood flow values obtained by simultaneous injection of two FM species correlated significantly $(r=0.96$, slope $=1.06$, intercept $=$ $0.05)$, the mean difference was $0.39 \pm 1.11 \mathrm{ml} / \mathrm{min} / 100 \mathrm{~g}$. Our data demonstrate that the measurement of RBBF by means of FM allows a valid determination of RBBF.

Copyright $\odot 2003$ S. Karger AG, Basel

\section{Introduction}

In 1967 Rudolph and Heymann [1] introduced radiolabelled microspheres and 1 year later Makowski et al. [2] reported the reference blood sample technique for the determination of regional organ blood flow (RBF). Using this method microspheres are delivered to the different organs by the arterial blood after injection into the left ventricle or atrium. Due to their diameter microspheres are trapped in the capillaries of the organs. During the

\section{KARGER}

Fax +41613061234

E-Mail karger@karger.ch

www.karger.com
(C) 2003 S. Karger AG, Basel

0014-312X/03/0354-0337\$19.50/0

Accessible online at:

www. karger.com/esr
Dr. med. Hermann Anetzberger

Department of Orthopedics

Marchioninistrasse 15

D-81377 Munich (Germany)

Tel./Fax +49 897095 5614, E-Mail Hermann.Anetzberger@helios.med.uni-muenchen.de 
injection of microspheres an arterial reference blood sample is withdrawn by means of a Harvard pump. The concentrations of microspheres in the reference blood sample and in the tissue samples were determined and the blood flow values were calculated.

However, due to the hazards inherent to radiolabelled microspheres, fluorescent microspheres (FMs) [3, 4] and colored microspheres $[5,6]$ were developed and validated for determination of RBF. These methods require complete recovery of the microspheres from the tissue and reference blood samples. Recent innovations such as the automation of the sample-processing procedure [7] and the development of the sample-processing unit (SPU) [8] have enabled the improvement and standardization of the FM technique for measurement of RBF, which has proven to be the most suitable technique for simultaneous determination of RBF in the heart, lung, kidney, muscle, brain and spleen $[3,4,9,10]$. Even though the use of FM for assessment of regional bone blood flow (RBBF) [11, 12] has been reported, the suitability of the reference blood sample technique for measurement of RBBF by means of FMs has not been demonstrated so far. In contrast to other organs, the application of the FM technique for bone tissue requires as a first step decalcification of samples with acids which may alter the fluorescence characteristics of the spheres. Therefore an in vitro study was undertaken to evaluate the possible influences of the decalcifying process on the fluorescence characteristics of the spheres.

Errors in blood flow studies using the microsphere reference sample technique are mainly due to stochastic error. To achieve valid blood flow data a sample should contain 384 spheres [13]. The number of spheres lodged in a tissue sample depends on hemodynamic parameters, tissue blood flow, tissue sample size and the number of totally injected spheres. As the sample size and number of spheres injected can be varied easily, we investigated the number of microspheres in large bone samples after injecting increasing dosages of FMs.

\section{Material and Methods}

\section{Quantification of the Fluorescence Intensity}

Seven differently labelled FM species (FluoSpheres ${ }^{\circledR}$, Molecular Probes, Eugene, Oreg., USA) were used in this study. FMs with a diameter of $15 \mu \mathrm{m}$ were delivered in a solution containing $0.15 \mathrm{M}$ $\mathrm{NaCl}$ and $0.05 \%$ Tween 20 .

To determine the number of spheres in tissue and reference blood samples, $1 \mathrm{ml}$ of the stock solution ( $\approx 10^{6}$ spheres) was diluted with $9 \mathrm{ml}$ of $0.9 \% \mathrm{NaCl}$. The number of spheres per microliter of this solu- tion was then determined using a flow cytometer [14]. With this method, impedance alterations dependent on the particle size between electrodes were analyzed and the number of particles was calculated automatically. Measurements were repeated 10 times for each FM species. The solution with a known amount of spheres was used for serial dilutions (7 dilution steps, 1:10 each). The fluorescence intensity of each resulting aliquot was measured and the data used to establish a standard curve. The slope of the standard curve served to calculate the number of FMs in the tissue samples. Each FM species ( $1 \mu \mathrm{l}$ of $1 \mathrm{ml}$ from a 1:10 diluted stock solution) was measured 10 times in order to determine the precision and reproducibility of the measurement of fluorescence (LS 50B, Perkin Elmer, Überlingen, Germany).

To test the stability of the FMs in acidic solution we compared the fluorescence intensity of $10-\mu \mathrm{l}$ aliquots measured directly and after storage for 4 weeks in $\mathrm{HCl}(1 \mathrm{~mol} / \mathrm{l})$. This procedure was repeated 10 times. In order to examine interference from calcium on the automated fluorescence intensity measurement the same procedure was repeated with bone tissue samples.

\section{Surgical Preparation}

Six adult, female New Zealand rabbits (Charles River, Kisslegg, Germany) with a mean body weight of $3.4 \pm 0.5 \mathrm{~kg}$ were used in this study which was authorized by the animal care committee of the local Bavarian government, Munich, Germany. The epiphysial plates were closed in each rabbit, as was verified during dissection of the bones. Preoperatively the animals were kept in groups on the ground and allowed free movement.

Animals were anesthetized by intramuscular injection of ketamine $\left(\right.$ Ketavet $^{\circledR}, 15 \mathrm{mg} / \mathrm{kg}$ body weight, Pharmacia \& Upjohn, Erlangen, Germany) and xylacin (Rompun ${ }^{\circledR}, 2 \mathrm{mg} / \mathrm{kg}$ BW, Bayer, Leverkusen, Germany) and allowed to spontaneously breath room air and supplemental oxygen ( 2 liter/min). Animals were fixed in the supine position, the right common carotid artery was isolated and a catheter (Cavafix ${ }^{\circledR}$ MT, flow rate $10 \mathrm{ml} / \mathrm{min}$; B. Braun Melsungen AG, Melsungen, Germany) inserted. A pressure-monitoring system (Sirecust 304 D, Siemens, Munich, Germany) was connected to the catheter. As this catheter served for the injection of FMs it was advanced into the left ventricle. The correct position of the catheter's tip was identified by the typical waveform of the left ventricular pressure curve. For the collection of the arterial blood sample a second catheter was introduced into the left carotid artery and advanced into the descending aorta. Blood pressure and heart rate were monitored continuously throughout the experiment. Blood losses were compensated by intravenous infusion of $0.9 \%$ saline $(15 \mathrm{ml} / \mathrm{h})$. Changes in systolic blood pressure of less than $\pm 15 \%$ and in heart rate of less than \pm 20 beats/min were tolerated. After the last injection of microspheres the animals were euthanized with an overdose of pentobarbital (Narcoren ${ }^{\circledR}$, Rhône Mérieux GmbH, Laupheim, Germany).

\section{Measurement of Regional Bone Blood Flow}

Prior to each injection, FMs were vortex mixed (Genie 2, Bender and Hobein AG, Zürich, Switzerland) for $3 \mathrm{~min}$ and sonicated (Sonorex TK52H, Bandelin, Germany) for $5 \mathrm{~min}$ again followed by $3 \mathrm{~min}$ of vortex mixing. FM species were selected randomly from the stock solution and diluted $1: 10$ in $0.9 \% \mathrm{NaCl}$.

In order to find the optimum dosage of microspheres needed for a valid measurement, animals were injected as follows: the 1st injection with $0.5 \times 10^{6} \mathrm{FM}$; the 2 nd with $1.0 \times 10^{6} \mathrm{FM}$; the 3 rd with 2.0 $\times 10^{6} \mathrm{FM}$, and the 4 th and 5 th with $3.0 \times 10^{6}$ microspheres. To test 
the precision of the measurement, the last injection was carried out with pairs of two FM species $\left(3 \times 10^{6}\right.$ spheres each). Prior to each injection the correct position of the catheter was controlled and blood pressure and heart rate were noted. Each injection lasted for $1 \mathrm{~min}$ and was carried out by the same person. A period of $20 \mathrm{~min}$ for stabilization was allowed to elapse between two consecutive injections. The withdrawal of the arterial reference blood sample from the catheter in the aorta was started $15 \mathrm{~s}$ before the injection of microspheres and continued for $2 \mathrm{~min}$. The withdrawal rate of the Harvard pump ('33' Syringe Pump, FMI, Egelsbach, Germany) was $3.54 \mathrm{ml} / \mathrm{min}$. Processing of reference blood and tissue samples was performed by our robot system [7] using the SPU (Gaiser, Kappel-Grafenhausen, Germany) developed by our group [8].

\section{Sample Processing}

At the end of the experiments organs were removed from the animals. To control for adequate mixing of the spheres in the arterial blood, both kidneys were taken and the connective tissue as well as the renal pelvis were removed. Each kidney was then dissected into 8 samples, resulting in a total of 96 samples from all experiments. The average weight of the right and left kidney samples was $1.30 \pm 0.37$ and $1.30 \pm 0.32 \mathrm{~g}$, respectively.

The femoral condyles and tibial plateaus were separated from the rest of the bones. Muscles, periost, ligaments as well as cartilage were removed with a scalpel and a bone curette. Left tibial and femoral bone samples were then divided into medial and lateral condyle. The mean weight of the tibial plateau and femoral condyle was $1.87 \pm$ 0.23 and $2.25 \pm 0.27 \mathrm{~g}$, respectively. The mean weight of the medial and lateral tibial condyles was $0.87 \pm 0.07$ and $0.95 \pm 0.16 \mathrm{~g}$, respectively, whereas medial and lateral femoral condyles weighed $1.13 \pm$ 0.26 and $1.05 \pm 0.22 \mathrm{~g}$, respectively.

The crystalline matrix of the bone samples was dissolved by soaking the samples in hydrochloric acid $(1 \mathrm{~mol} / \mathrm{l})$ for a period of 4 weeks. The organic matrix was then digested with a mixture of $\mathrm{KOH}$ ( $4 \mathrm{~mol} / \mathrm{l}$ ), Tween 80 and isopropyl alcohol at $60^{\circ} \mathrm{C}$ and the FMs isolated by filtering the digested material by means of the SPU according to the protocol of Thein et al. [7]. The tissue sample-processing procedure including sample digestion, FM isolation and online measurement of the fluorescence intensity was carried out by an automated procedure [8].

Samples of kidneys were processed as described above immediately after the dissection. The fluorescence intensity of the arterial reference blood samples was measured after filtering the blood through the filter within the SPU. To render the blood filterable, 1 vol blood was diluted with 2 vol of sodium citrate.

The data from the fluorescence measurements served to calculate the blood flow values $(\mathrm{ml} / \mathrm{min} / 100 \mathrm{~g})$ for each tissue sample and injection interval according to the formula:

$$
\mathrm{F}_{\text {sample }}=\mathrm{F}_{\text {reference }} \times \frac{\mathrm{N}_{\text {sample }}}{\mathrm{N}_{\text {reference }}}
$$

where: $F_{\text {sample }}=$ blood flow in the sample in $\mathrm{ml} / \mathrm{min}$; $F_{\text {reference }}=$ withdrawal rate of the Harvard pump (3.54 $\mathrm{ml} / \mathrm{min}) ; \mathrm{N}_{\text {sample }}=$ number (intensity) of MS in the sample, and $\mathrm{N}_{\text {reference }}=$ number (intensity) of MS in the reference sample.

To allow the comparison of different samples, the calculated blood flow values were divided by the tissue weight and normalized to $100 \mathrm{~g}$, giving the blood flow value $(\mathrm{ml} / \mathrm{min} / 100 \mathrm{~g})$.

Regional Bone Blood Flow

\section{Statistical Analysis}

The statistical analyses were carried out with the software SPSS for Windows, Version 11.0 (SPSS Inc., Chicago, Ill., USA). To evaluate the fluorescent intensity per sphere, linear regression analysis was used to estimate the slope summarizing the relationship between the fluorescence intensity and the number of spheres. The coefficient of correlation (r), the coefficient of determination $\left(\mathrm{r}^{2}\right)$ and the standard error of the estimate were computed for all pairs. Slopes and intercepts were compared to unity and 0 , respectively, for a two-sided $95 \%$ confidence interval.

The relative coefficient of variation in percent $\left(\mathrm{rel} \mathrm{CV}=\mathrm{CV} / \mathrm{n}^{0.5}\right.$ $\times 100$ ) was used to characterize the precision of repeated measurements. To compare the fluorescence intensity in samples treated with and without $\mathrm{HCl}$, Student's test was used. RBBF values determined after simultaneous injection of FMs were compared using leastsquares linear regression and the method of Bland and Altman [15].

ANOVA according to Friedman was used to determine the significance of differences in mean RBBF of the repeated injections. The statistical significance of the differences in blood flow values from the femur and tibia and the medial and lateral condyles of the femur and the tibia was assessed using Wilcoxon signed rank test. A p value of $<0.05$ was considered significant.

\section{Results}

\section{Quantification of Fluorescence in Microspheres}

The number of spheres per milliliter of the stock solution for various FM species was as follows: $1.07 \pm 0.05 \times$ $10^{6}$ for blue; $0.92 \pm 0.03 \times 10^{6}$ for blue green; $1.25 \pm$ $0.08 \times 10^{6}$ for yellow green; $0.32 \pm 0.01 \times 10^{6} ; 0.56 \pm$ $0.01 \times 10^{6}$ for red; $0.38 \pm 0.03 \times 10^{6}$ for crimson, and $0.81 \pm 0.02 \times 10^{6}$. The relative $\mathrm{CV}$ for counting the microspheres with the flow cytometer ranged between $0.7 \%$ (red) and $2.2 \%$ (crimson).

To evaluate the fluorescence intensity per sphere linear regression analysis was used to estimate the slope between the fluorescence intensity and the number of spheres in serial dilutions. The within precision values, given as the square of the correlation coefficient, varied between 0.985 and 0.998 (all $\mathrm{p}<0.001)$. The confidence intervals of the intercept of all colors included 0 . The data of the regression analysis are given in table 1.

\section{Influence of $\mathrm{HCl}$ on the Fluorescence Intensity of FMs}

In order to examine the possible interference of acid $(\mathrm{HCl})$ which is required to decalcify the bone samples, the fluorescence intensity in FM species was analyzed under defined conditions. The relative $\mathrm{CV}$ from 10 repeated measurements of $1 \mu \mathrm{l}$ of the same aliquot was $0.2 \%$ for each FM species. The relative CV calculated from 10 aliquots $(10 \mu \mathrm{l})$ taken from a diluted stock solution varied between 1.9 and $5.9 \%$. The relative CV for scarlet-colored FM was 2-fold higher than for the other colors. No signifi- 
Table 1. Results of the regression analysis between fluorescence intensity and the number of spheres in a serial dilution of each FM species

\begin{tabular}{lllrlc}
\hline FM & $r$ & $r^{2}$ & SEE & $\begin{array}{l}\text { Slope } \\
(95 \% \mathrm{CI})\end{array}$ & $\begin{array}{l}\text { Intercept } \\
(95 \% \mathrm{CI})\end{array}$ \\
\hline Blue & 0.998 & 0.996 & 10 & $0.017(0.015-0.018)$ & $0(-12-12)$ \\
Blue green & 0.993 & 0.985 & 10 & $0.016(0.013-0.018)$ & $11(-4-25)$ \\
Yellow green & 0.999 & 0.998 & 25 & $0.052(0.049-0.055)$ & $26(-11-63)$ \\
Orange & 0.996 & 0.991 & 7 & $0.030(0.026-0.033)$ & $2(-6-11)$ \\
Red & 0.999 & 0.997 & 4 & $0.016(0.015-0.017)$ & $2(-3-7)$ \\
Crimson & 0.998 & 0.995 & 9 & $0.044(0.041-0.048)$ & $-3(-13-8)$ \\
Scarlet & 0.998 & 0.996 & 16 & $0.037(0.034-0.040)$ & $-8(-27-12)$ \\
\hline
\end{tabular}

$\mathrm{SEE}=$ Standard error of the estimate.
Table 2. Relative coefficient of variation (in \%) of each FM species

\begin{tabular}{lllll}
\hline Color & FM1 & FM1 $+\mathrm{HCl}$ & FM2 & FM2 + HCl + bone \\
\hline Blue & 3.8 & 3.8 & 2.8 & 2.8 \\
Blue green & 2.7 & 2.8 & 1.9 & 1.6 \\
Yellow green & 3.1 & 2.6 & 2.4 & 1.4 \\
Orange & 3.5 & 3.4 & 2.1 & 1.6 \\
Red & 3.4 & 3.2 & 2.4 & 1.6 \\
Crimson & 3.5 & 3.3 & 3.2 & 2.6 \\
Scarlet & 5.9 & 5.6 & 5.5 & 4.3
\end{tabular}

Data are calculated by measuring the fluorescence intensity of $10 \mu \mathrm{l}$ FM1 $(\mathrm{n}=10)$ without $\mathrm{HCl}$ and $10 \mu \mathrm{FM} 1(\mathrm{n}=10)$ after 4 weeks storage in $\mathrm{HCl}$ and from $10 \mu 1 \mathrm{FM} 2(\mathrm{n}=10)$ without $\mathrm{HCl}$ and $10 \mu \mathrm{FM} 2(\mathrm{n}=10)$ after 4 weeks storage in $\mathrm{HCl}$ together with bone samples.

Table 3. Number of FMs in the samples of different tissues after injection of $0.5 \times 10^{6}, 1.0 \times 10^{6}, 2.0 \times 10^{6}$ and $3.0 \times 10^{6}$, respectively $(n=6 ;$ mean $\pm \mathrm{SD})$

\begin{tabular}{|c|c|c|c|c|}
\hline \multirow[t]{2}{*}{ Tissues } & \multicolumn{4}{|l|}{ FMs injected } \\
\hline & $0.5 \times 10^{6}$ & $1.0 \times 10^{6}$ & $2.0 \times 10^{6}$ & $3.0 \times 10^{6}$ \\
\hline Kidney right & $6.4 \pm 2.7 \times 10^{3}$ & $11.3 \pm 4.7 \times 10^{3}$ & $16.0 \pm 6.0 \times 10^{3}$ & $23.2 \pm 10.6 \times 10^{3}$ \\
\hline Kidney left & $6.4 \pm 2.2 \times 10^{3}$ & $11.8 \pm 3.9 \times 10^{3}$ & $17.1 \pm 4.9 \times 10^{3}$ & $24.0 \pm 11.6 \times 10^{3}$ \\
\hline FC right & $155 \pm 46$ & $253 \pm 45$ & $399 \pm 124$ & $846 \pm 288$ \\
\hline TC right & $213 \pm 44$ & $338 \pm 73$ & $648 \pm 216$ & $1,064 \pm 363$ \\
\hline $\mathrm{FC}_{\text {med }}$ left & $93 \pm 41$ & $140 \pm 49$ & $238 \pm 104$ & $578 \pm 266$ \\
\hline $\mathrm{FC}_{\text {lat }}$ left & $54 \pm 26$ & $91 \pm 46$ & $152 \pm 57$ & $376 \pm 84$ \\
\hline $\mathrm{TC}_{\mathrm{med}}$ left & $109 \pm 53$ & $197 \pm 69$ & $317 \pm 136$ & $609 \pm 240$ \\
\hline $\mathrm{TC}_{\text {lat }}$ left & $80 \pm 52$ & $162 \pm 87$ & $291 \pm 150$ & $559 \pm 324$ \\
\hline
\end{tabular}

The number of FMs in the kidneys represents the summation of 8 samples. $\mathrm{FC}=$ Femoral condyles; $\mathrm{TC}=$ tibial condyles; $\mathrm{FC}_{\mathrm{med}}=$ medial femoral condyle $; \mathrm{FC}_{\mathrm{lat}}=$ lateral femoral condyle; $\mathrm{TC}_{\mathrm{med}}=$ medial tibial condyle; $\mathrm{TC}_{\mathrm{lat}}=$ lateral tibial condyle. 
Fig. 1. a Regional bone blood flow values of bone samples obtained by simultaneous injection of two FM species are plotted on $\mathrm{x}$ axis and y axis. $-=$ Slope of linear relationship $\left(\mathrm{n}=35, \mathrm{r}=0.96, \mathrm{r}^{2}=0.92\right.$, $\mathrm{y}=1.06 \mathrm{x}+0.05) ;---=$ isometric line $(\mathrm{y}=$ $1 \mathrm{x}+0)$. $\mathbf{b}$ The Bland and Altman comparison is shown as the difference of the flow determined by FM1 and FM2. $-=$ Mean difference in $\mathrm{ml} / \mathrm{min} / 100 \mathrm{~g} ;---= \pm 2$ standard deviations.
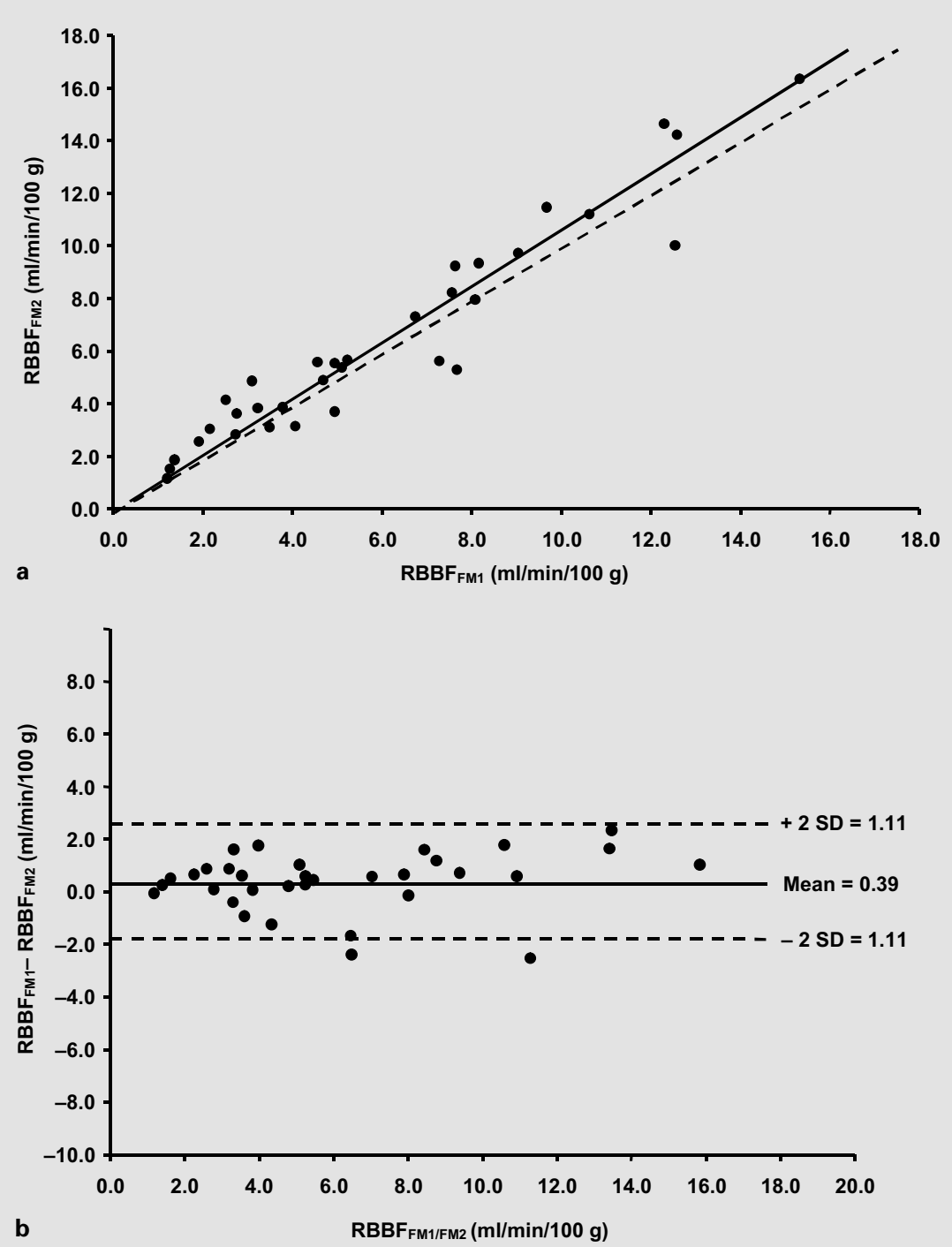

b cant differences in fluorescence intensity was noted in samples which were kept in $\mathrm{HCl}(1 \mathrm{~mol} / \mathrm{l})$ with or without bone samples for 4 weeks (table 2 ).

\section{Number of Spheres in Various Bone Samples}

Animals injected with $0.5 \times 10^{6}$ spheres accumulated $213 \pm 44$ spheres in tibial and $155 \pm 46$ spheres in femoral condyles. Increasing the number of FMs injected consequently lead to a higher number of microspheres in the bone samples. When $2.0 \times 10^{6} \mathrm{FMs}$ were injected $648 \pm$ 216 and $399 \pm 124$ FMs accumulated in tibial and femoral samples, respectively. Injection of $3.0 \times 10^{6} \mathrm{FMs}$ led to accumulation of $609 \pm 240$ in medial tibial condyle and $559 \pm 324$ in the lateral tibial condyle, whereas in the medial femoral condyle $578 \pm 266$ and in the lateral femoral condyle $376 \pm 84$ spheres were found (table 3 ).

\section{Reproducibility of Blood Flow Measurements}

The blood flow values of the bone samples determined by simultaneous injection of two FM correlated significantly $\left(r=0.96, r^{2}=0.92, y=1.06 x+0.05\right.$; fig. 1a). The slope was close to 1 and the intercept close to 0 . The comparison of Bland and Altman [15] showed a mean difference of $0.39 \pm 1.11 \mathrm{ml} / \mathrm{min} / 100 \mathrm{~g}$ (fig. $1 \mathrm{~b}$ ). 


\section{Regional Blood Flow}

For the evaluation of RBBF, data from samples containing 400 spheres are presented in order to ascertain the validity of the measurement [16]. Mean arterial blood pressure ranged between $64 \pm 13$ (5th injection) and 71

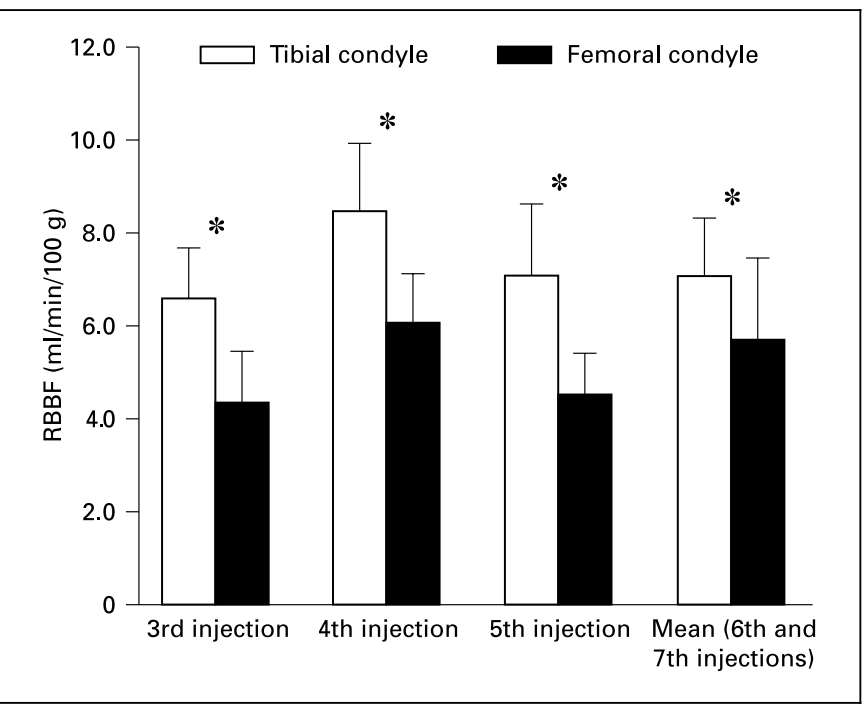

Fig. 2. Blood flow values of the tibial and femoral condyles. Values are given as mean \pm SEM. $*$ RBBF of the tibia was significantly higher than in the femur after each injection. $\pm 12 \mathrm{~mm} \mathrm{Hg}$ (2nd injection) but did not change significantly throughout the experiments. Renal blood flow values remained between $2.5 \pm 0.9$ and $2.9 \pm 0.4 \mathrm{ml} / \mathrm{min} / \mathrm{g}$. No significant differences were observed between the individual injections and between blood flow values of left and right kidney. Blood flow values of the tibial condyle $(6.6 \pm 1.1$ to $8.5 \pm 1.4 \mathrm{ml} / \mathrm{min} / 100 \mathrm{~g})$ and femoral condyle $(4.3 \pm 1.1$ to $6.0 \pm 1.1 \mathrm{ml} / \mathrm{min} / 100 \mathrm{~g})$ were not different between the various time intervals during the experiments (fig. 2). The RBBF of the femoral condyle was significantly lower than that of the tibial condyle at each time point (fig. 2). The blood flow of the medial tibial condyle was between $8.0 \pm 2.2$ and $10.8 \pm 2.0 \mathrm{ml} /$ $\mathrm{min} / 100 \mathrm{~g}$ and slightly higher than that of the lateral tibial condyle (between $7.5 \pm 1.6$ and $9.0 \pm 2.2 \mathrm{ml} / \mathrm{min} / 100 \mathrm{~g}$ ). However, these differences were statistically not significant. The medial and lateral femoral condyle blood flow values varied between $5.5 \pm 1.5$ and $6.8 \pm 1.6$, and $3.8 \pm$ 1.4 and $5.2 \pm 0.3 \mathrm{ml} / \mathrm{min} / 100 \mathrm{~g}$, respectively (fig. 3).

\section{Discussion}

\section{Adequacy of the Model}

In contrast to other organs, determination of the regional blood flow in the bone is influenced by technical difficulties because of the compact architecture of the tissue. Despite the fact that numerous techniques have been
Fig. 3. Blood flow values of the medial and lateral tibial condyles, and the medial and lateral femoral condyles. Values are given as mean \pm SEM. Blood flow values of the lateral condyles were slightly lower than of the medial condyles, but the difference was not significant.

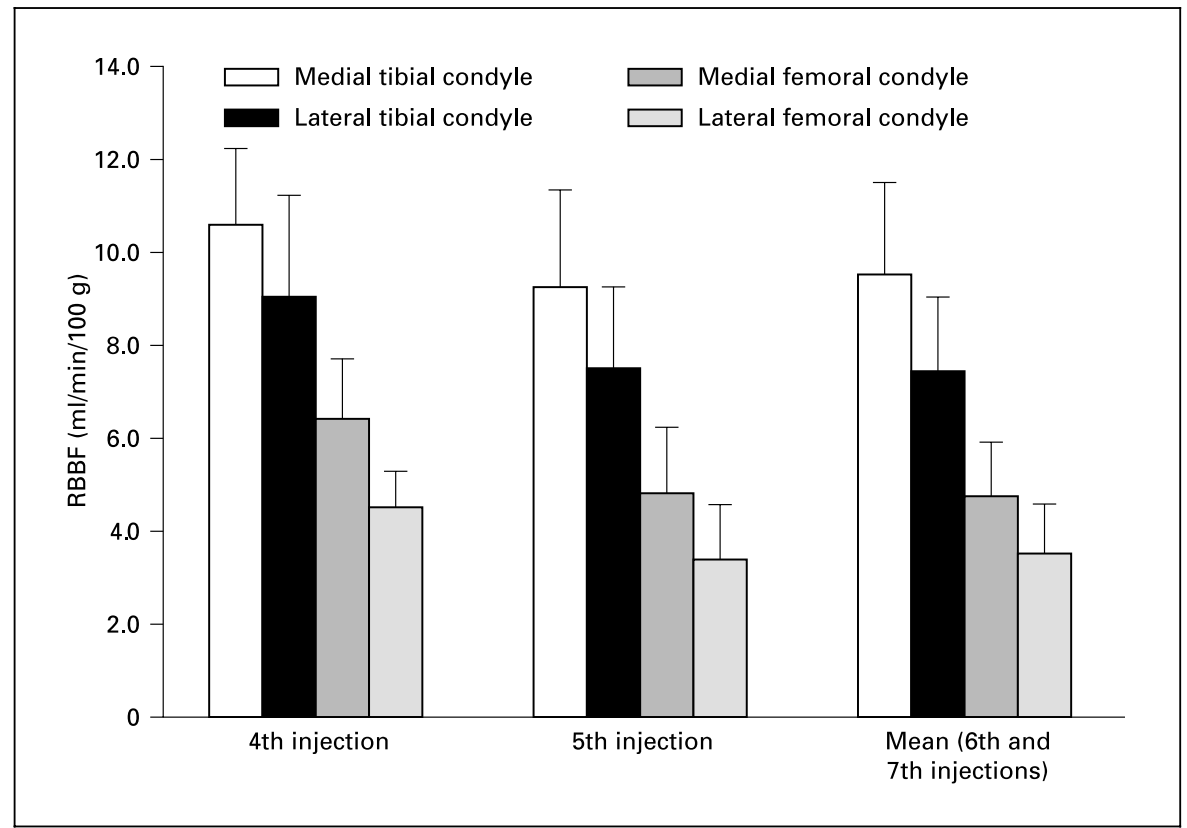

Anetzberger/Thein/Walli/Messmer 
applied to study the microcirculation of the bone, only a few have yielded valid RBBF values. The advantages and disadvantages of the different methods have been discussed by several authors [17-20]. The determination of RBBF by microvascular entrapment of microspheres has various advantages. It is possible to carry out repetitive measurements within the same animal without surgical manipulation of the bone. However, to minimize errors in blood flow determination by means of microspheres (reference sample technique), some precautions have to be taken into consideration: (1) microspheres have to be mixed homogeneously in the arterial blood; (2) shunting of microspheres from the site of entrapment should be negligible; (3) arterial blockade of the capillary bed should not alter microcirculation; (4) according to Buckberg et al. [13], 384 microspheres have to be present in an individual tissue sample, and (5) recirculation of microspheres should not occur.

In our experimental setup FMs were injected into the left ventricle to assure homogeneous dispersion of the spheres in the blood [13]. No differences in regional blood flow of the right and left kidneys were observed indicating adequate mixing of FMs in the blood. In contrast to injection of the spheres into the aorta which only allows measurement of the RBBF in the lower extremities [21], injection into the ventricle enables measurement of the RBBF of the thoracic organs and the upper extremities. In addition, the reference blood sample can be obtained via a carotid artery thereby avoiding disturbance of the microcirculation of the hind limb by reference sampling via a femoral artery.

The spheres are completely retained in the capillaries of the lung thereby excluding the possibility of recirculation of spheres $[22,23]$. Shunting of spheres has been described in detail [24]. About 1-4\% of the injected microspheres with a diameter of $15 \mu \mathrm{m}$ shunt through the vessels of a healthy bone [25, 26]. We have not observed statistically significant changes in systemic hemodynamic parameters after repeated injections of $15.5 \times 10^{6}$ spheres. This is in agreement with findings of other authors [27, 28].

\section{Errors due to Sample Processing}

Although the use of FMs has been validated for numerous organs $[3,4]$, there are only a few reports on the measurement of bone blood flow [11,29-31]. In these studies the number of FMs was determined either with a fluorescence microscope $[11,30]$ or by extracting the fluorescent dyes from the FMs without prior digestion of the tissue [29], which may not assure quantitative recovery of fluo- rescence from microspheres. In our study the loss of FM was minimized by using the SPU, decalcification and an automated sample-processing technique [7, 8]. The relative CV for measurement of fluorescence was $0.2 \%$ for each $\mathrm{FM}$ species, indicating that $\mathrm{HCl}$ used to dissolve the crystalline matrix did not alter the fluorescence characteristics of the FMs. We observed a higher CV for scarletcolored FMs. This is in accordance with Schimmel et al. [32], who also found a higher methodological error using scarlet-colored FMs. However, there is still no explanation for this finding.

\section{Number of Spheres per Sample and Precision of RBBF Measurements}

In 1971 Buckberg et al. [13] showed that a minimum of 384 microspheres has to be present in an individual sample to achieve reliable blood flow values. However, other authors pointed out that fewer spheres present in an individual sample may still enable the detection of flow heterogeneity $[16,33,34]$. Nevertheless to detect flow changes in single tissue samples as we do, application of the 400 rule is more reliable. Our results indicate that at least 3.0 $\times 10^{6}$ FMs have to be injected into rabbits with a body weight of $3 \mathrm{~kg}$ to guarantee a sufficient number of spheres per bone sample $\left(\approx 1.0 \times 10^{6} / \mathrm{kg}\right.$ body weight $)$.

To test the precision of our approach, the last FM injection was carried out by injecting two different FM species simultaneously. RBBF values obtained by simultaneously injected FMs showed a highly significant linear correlation. The slope was close to 1 and the intercept was close to 0 . The Bland and Altman comparison for all bone samples showed a mean difference of $0.39 \mathrm{ml} / \mathrm{min} / 100 \mathrm{~g}$ and a uniform distribution of scatter above and below 0 , indicating the validity of the measurement.

The blood flow values of the femoral and the tibial condyles obtained in this study are in accordance with earlier reports [12]. We have confirmed the data of Okubo et al. [35], who also reported higher blood flow values in the tibial as compared to the femoral condyles. In contrast to McGrory et al. [36], we did not observe changes of RBBF over a period of $60 \mathrm{~min}$.

$\mathrm{RBBF}$ is influenced by physiological, humoral and neurogenic stimuli. Gross et al. [25], using radioactive spheres, observed a reduction in RBBF under hypotension, hypoxia and acidosis, which they explained by an increase in vascular resistance. The influence of neurogenic factors and the effect of exercise are unclear [25, 3740]. In order to detect minimal changes in RBBF under physiological and pathological conditions, the experiments should be standardized as much as possible. To 
evaluate the systemic hemodynamic conditions at the time of injection, arterial blood pressure and cardiac output should be measured. Cardiac output can easily be determined post hoc by the number of spheres injected, the number of spheres in the reference blood sample and the withdrawal rate of the Harvard pump [23]. However, values of cardiac output calculated in this manner have to be interpreted critically, as the number of spheres in the stock solution may vary after repeated withdrawals of spheres despite adequate vortex mixing and sonication of microspheres. Therefore the number of spheres injected should always be determined by analysing an aliquot of the injected volume.

\section{Conclusions}

We could show that decalcification of the bone by means of $\mathrm{HCl}$ does not influence the fluorescence characteristics of the FMs. The remaining tissue can be digested completely as reported previously by our group. Injection of at least $2 \times 10^{6} \mathrm{FMs}$ is needed to achieve a local deposition of at least 400 spheres in femoral and tibial condyles. For smaller samples, e.g. medial and lateral condyles, injection of $3 \times 10^{6} \mathrm{FMs}$ is recommended. These two findings together with complete recovery of FMs from the tissue and reference blood samples as demonstrated here render the FM method a reliable and valid technique for the measurement of regional blood flow in bone tissue.

\section{References}

1 Rudolph AM, Heymann MA: The circulation of the fetus in utero. Methods for studying distribution of blood flow, cardiac output and organ blood flow. Circ Res 1967;21:163-184.

2 Makowski EL, Meschia G, Droegemueller W, Battaglia FC: Measurement of umbilical arterial blood flow to the sheep placenta and fetus in utero. Distribution to cotyledons and the intercotyledonary chorion. Circ Res 1968;23:623631.

3 Van Oosterhout MF, Prinzen FW, Sakurada S, Glenny RW, Hales JR: Fluorescent microspheres are superior to radioactive microspheres in chronic blood flow measurements. Am J Physiol 1998;275:H110-H115.

4 Glenny RW, Bernard S, Brinkley M: Validation of fluorescent-labeled microspheres for measurement of regional organ perfusion. $\mathrm{J}$ Appl Physiol 1993;74:2585-2597.

5 Kowallik P, Schulz R, Guth BD, Schade A, Paffhausen W, Gross R, Heusch G: Measurement of regional myocardial blood flow with multiple colored microspheres. Circulation 1991;83:974-982.

6 Walter B, Bauer R, Gaser E, Zwiener U: Validation of the multiple colored microsphere technique for regional blood flow measurements in newborn piglets. Basic Res Cardiol 1997;92:191-200.

7 Thein E, Raab S, Harris AG, Messmer K: Automation of the use of fluorescent microspheres for the determination of blood flow. Comput Methods Programs Biomed 2000;61: 11-21.

8 Raab S, Thein E, Harris AG, Messmer K: A new sample-processing unit for the fluorescent microsphere method. Am J Physiol 1999;276: H1801-H1806.

9 Thein E, Raab S, Harris AG, Kleen M, Habler $\mathrm{O}$, Meisner F, Messmer K: Comparison of regional blood flow values measured by radioactive and fluorescent microspheres. Eur Surg Res 2002;34:215-223.
10 Zwissler B, Schosser R, Weiss C, Iber V, Weiss M, Schwickert C, Spengler P, Messmer K: Methodological error and spatial variability of organ blood flow measurements using radiolabeled microspheres. Res Exp Med (Berl) 1991; 191:47-63.

11 Nolte D, Raab S, Thein E, Draenert K, Ehrenfeld M, Messmer K: A new experimental model for repetitive osseous blood supply measurement. Mund Kiefer Gesichtschir 1999;3(suppl 1):147-150.

12 Shymkiw RC, Bray RC, Boyd SK, Kantzas A, Zernicke RF: Physiological and mechanical adaptation of periarticular cancellous bone after joint ligament injury. J Appl Physiol 2001;90: 1083-1087.

13 Buckberg GD, Luck JC, Payne DB, Hoffman JI, Archie JP, Fixler DE: Some sources of error in measuring regional blood flow with radioactive microspheres. J Appl Physiol 1971;31: 598-604.

14 Wietzorrek J, Plesnila N, Baethmann A, Kachel V: A new multiparameter flow cytometer: Optical and electrical cell analysis in combination with video microscopy in flow. Cytometry 1999;35:291-301.

15 Bland JM, Altman DG: Statistical methods for assessing agreement between two methods of clinical measurement. Lancet 1986;i:307-310.

16 Nose Y, Nakamura T, Nakamura M: The microsphere method facilitates statistical assessment of regional blood flow. Basic Res Cardiol 1985;80:417-429.

17 Kane WJ: Fundamental concepts in boneblood flow studies. J Bone Joint Surg Am 1968; 50:801-811.

18 Schoutens A, Bergmann P, Verhas M: Bone blood flow measured by $85 \mathrm{Sr}$ microspheres and bone seeker clearances in the rat. Am J Physiol 1979;236:H1-H6.
19 Gross PM, Marcus ML, Heistad DD: Measurement of blood flow to bone and marrow in experimental animals by means of the microsphere technique. J Bone Joint Surg Am 1981; 63:1028-1031.

20 Brookes M, Revell WJ: Blood Supply of Bone, ed 2. Berlin, Springer, 1998.

21 Lunde PK, Michelsen K: Determination of cortical blood flow in rabbit femur by radioactive microspheres. Acta Physiol Scand 1970;80:3944.

22 Wagner HN Jr, Rhodes BA, Sasaki Y, Ryan JP: Studies of the circulation with radioactive microspheres. Invest Radiol 1969;4:374-386.

23 Archie JPJ, Fixler DE, Ullyot DJ, Hoffman JI, Utley JR, Carlson EL: Measurement of cardiac output with and organ trapping of radioactive microspheres. J Appl Physiol 1973;35:148154.

24 Consigny PM, Verrier ED, Payne BD, Edelist G, Jester J, Baer RW, Vlahakes GJ, Hoffman JI: Acute and chronic microsphere loss from canine left ventricular myocardium. Am J Physiol 1982;242:H392-H404.

25 Gross PM, Heistad DD, Marcus ML: Neurohumoral regulation of blood flow to bones and marrow. Am J Physiol 1979;237:H440-H448.

26 Hansen ES, He SZ, Hjortdal VE, Kjolseth D, Soballe K: Distribution of blood flow in normal and arthritic joints. Role of arteriovenous shunting studied in growing dogs. Am J Physiol 1992;262:H38-H46.

27 Baer RW, Payne BD, Verrier ED, Vlahakes GJ, Molodowitch D, Uhlig PN, Hoffman JI: Increased number of myocardial blood flow measurements with radionuclide-labeled microspheres. Am J Physiol 1984;246:H418-H434.

28 von Ritter C, Hinder RA, Womack W, Bauerfeind P, Fimmel CJ, Kvietys PR, Granger DN, Blum AL: Microsphere estimates of blood flow: Methodological considerations. Am J Physiol 1988;254:G275-G279. 
29 Tan W, Riggs KW, Thies RL, Rurak DW: Use of an automated fluorescent microsphere method to measure regional blood flow in the fetal lamb. Can J Physiol Pharmacol 1997;75: 959-968.

30 Gross TS, Damji AA, Judex S, Bray RC, Zernicke RF: Bone hyperemia precedes disuseinduced intracortical bone resorption. J Appl Physiol 1999;86:230-235.

31 Schimmel C, Frazer D, Glenny RW: Extending fluorescent microsphere methods for regional organ blood flow to 13 simultaneous colors. Am J Physiol Heart Circ Physiol 2001;280: H2496-H2506.

32 Schimmel C, Frazer D, Huckins SR, Glenny RW: Validation of automated spectrofluoroimetry for measurement of regional organ perfusion using fluorescent microspheres. Comput Methods Programs Biomed 2000;62:115-125.
33 Li G, Bronk JT, Kelly PJ: Canine bone blood flow estimated with microspheres. J Orthop Res 1989;7:61-67.

34 Polissar NL, Stanford DC, Glenny RW: The 400 microsphere per piece 'rule' does not apply to all blood flow studies. Am J Physiol Heart Circ Physiol 2000;278:H16-H25.

35 Okubo M, Kinoshita T, Yukimura T, Abe Y, Shimazu A: Experimental study of measurement of regional bone blood flow in the adult mongrel dog using radioactive microspheres. Clin Orthop 1979;138:263-270.

36 McGrory BJ, Moran CG, Bronk J, Weaver AL, Wood MB: Canine bone blood flow measurements using serial microsphere injections. Clin Orthop 1994;303:264-279.
37 Shim SS, Copp DH, Patterson FP: Bone blood flow in the limb following complete sciatic nerve section. Surg Gynecol Obstet 1966;123: 333-335.

38 Tondevold E, Bulow J: Bone blood flow in conscious dogs at rest and during exercise. Acta Orthop Scand 1983;54:53-57.

39 Davies R, Tothill P, Hooper G, Fleming RH, McCarthy ID, Hughes SP: The early effects of sympathectomy on bone blood flow. Calcif Tissue Int 1984;36:622-624.

40 Ferrell WR, Khoshbaten A, Angerson WJ: Responses of bone and joint blood vessels in cats and rabbits to electrical stimulation of nerves supplying the knee. J Physiol 1990;431:677687. 